MATERIALS RESEARCH COMMUNICATIONS

Vol. 1, No. 1 (2020) (8 pages)

@ Pusat Publikasi Ilmiah ITS

\title{
STUDY OF AISI 1020 STEEL CHARACTERIZATION BY ZINC- ELECTROPLATING TREATMENT
}

\author{
VANIA MITHA PRATIWI* \\ Department of Materials and Metallurgical Engineering \\ Institut Teknologi Sepuluh Nopember \\ Jl. Teknik Kimia, Keputih, 60111, Surabaya,East Java, Indonesia \\ vaniamithapratiwi@gmail.com \\ * Corresponding author
}

Published 31 January 2020

\begin{abstract}
AISI 1020 steel is low carbon steel with a carbon content of $0.20 \%$. Before the steel is applied it is usually done metal finishing to improve its quality such as corrosion-resistant properties, appearance, toughness, electrical conductivity, and other properties. One way of metal finishing is by electroplating. Electroplating with zinc coating material is widely applied because zinc is a corrosion resistant steel coating, producing a good surface appearance, and the price is quite affordable. Based on the description above, the influence of temperature and time of zinc electroplating process on thickness, adhesion, and corrosion resistance of AISI 1020 steel was studied. Temperature variations to be used are 25,30 , and $35^{\circ} \mathrm{C}$. While for time variations are 9 , 12, and 15 minutes. The measurement of the thickness of the zinc layer was carried out using a DFT test, to find out the strength of the pulling carried out Pull-Off testing, and to obtain the value of the corrosion rate carried out by immersion testing and then calculated using weight loss method. The highest thickness value is $28.1333 \mu \mathrm{m}$ with variation of temperature is $35^{\circ} \mathrm{C}$ with 15 minutes plating time. The highest adhesive strength value is $15.595 \mathrm{MPa}$ with a temperature variation of $25^{\circ} \mathrm{C}$ and 9 minutes plating time. The lowest corrosion rate value is $0.0097 \mathrm{mmpy}$ with a temperature variation of $35^{\circ} \mathrm{C}$ and 15 minutes plating time.
\end{abstract}

Keywords: Time; temperature; Zinc; electroplating; corrosion rate; AISI 1020 steel

\section{Introduction}

Industry grew rapidly. The most widely used and varied materials are metal (steel). Ranging from household appliances, industries, medical equipment, agriculture, and many more products made of steel material (Wiewiorowska, 2015). Steel is a metal forming of iron and carbon that may contain several other elements (Callister, 2014). The Low carbon steel is a steel that has a carbon level (\% C) less than $0.3 \%$. This type of steel is more widely used because the low carbon steel has high durability, but the hardness is low and also not good on wear resistant (Giurlani, 2017). AISI 1020 Steel belongs to the category of low carbon steel with carbon content of $0.20 \%$. This type of steel is often used as a pipe making material for low and medium pressure fluids, boiler pipes, and also for hot steam canning pipes commonly used on power generation systems in the long term use of this steel can be Degradation and also damage caused by corrosion (Verhoven, 2017).

In the process of application, generally steel needs a metal finishing process to improve its quality such as corrosion resistance, appearance, toughness, electrical power, and other properties. One of them is metal finishing is metal plating. This method is done by coating the metal with other materials with various methods such as by using electricity (electroplating), Hot dip (hot Dipp), and also with spray (metal spraying) (Ndariyono, 2011). In 2016 Kadhim Alsultani conducted research on the influence of time variations on the thickness of zinc coating by electroplating method. The research shows that the longer the time the resulting electroplating thickness of zinc coating is increased (Alsultani, 2016). In 2015 Hong-Bok Choe conducted research on the influence of zinc metal spraying on the corrosion resistance properties of a steel. The study showed that steel that has been coated with a spraying zinc has better corrosion resistance properties (Hong Bok Choe, 2015). In 2010 Adetunji did research on the influence of zinc plating with a method of hot dip against corrosion resistance properties in a steel. The results of the study showed that steel has been coated with hot dip zinc with better corrosion resistance (Adetunji, 2010). 


\section{MATERIALS RESEARCH COMMUNICATIONS 1(1) (2020) 34-41}

Vania

Coating by means of electroplating is more liked because it has some advantages such as more evenly coating, as well as having adhesiveness and surface looks better. Electroplating can be done to coat the metal with different types of metals such as copper, nickel, zinc, tin, Chrome and others. From different types of zinc coating metal has some advantages. Zinc is a corrosion resistant coating that produces a good surface, and the price is quite affordable (Clifford, 2011). In this study conducted the effect of temperature influence and plating time to the thickness, adhesiveness, and corrosion resistance of zinc coating formed on AISI 1020 steel from the electroplating process.

\section{Experimental Method}

\subsection{Materials Preparation}

Before the process of electroplating carried out the specimen should be prepared first to facilitate the process of research. In addition, preparation is also useful to homogenate the initial state of the specimen so that the research results performed better and more accurately. In the first phase, a specimen was made by cutting AISI 1020 with a size of $40 \times 45 \times 4 \mathrm{~mm}$. Furthermore, the surface of the specimen is soften using sandpaper to be homogeneous. After that, the pickling process is to soak specimens in a $30 \% \mathrm{HCl}$ solution for 15 to 20 minutes. This process is done to clean the specimen surface of impurities that stick like corrosion products. To remove impurities such as oil or grease on the surface of the specimen carried out a degreasing process by soaking the specimen in a solution liquid $\mathrm{NaOH}$ $10 \%$ while wiping the surface of the specimen using a cleaning cloth. After that the specimen is rinsed using demineralized water then dried.

After the preparation of the specimen carried out further, conducted electrolyte solution as much as 1 liter with boric acid composition as much as 30 grams, zinc chloride as much as 55 grams, potassium chloride as much as 175 gram, 290 carrier as much $30 \mathrm{ml}$, and 290 maintenance as much as $2 \mathrm{ml}$. To facilitate the dissolving process when stirring the heated solution until the temperature reaches about $50-60^{\circ} \mathrm{C}$.

After the electrolyte solution is ready for the next specimen and zinc metal is hung until the position is hovering in electrolyte solution. The test specimen is connected by a negative current, while the zinc metal is connected with a positive current on the rectifier. Furthermore, the process of electroplating by regulating voltage of 2 Volt, with a variation of temperature of 25,30 , and $350 \mathrm{C}$ and with a variation of time of 9,12 , and 15 minutes.

\subsection{Materials characterization}

After the electroplating process finished the next several tests on the specimen test. SEM-EDX testing is performed to determine the characteristics of the resulting zinc coating result. Thickness testing is done using the DFT Test tool. In this thickness test, the measurements were measured at three points, two points in each of the edges or ends of the specimen, and one point in the center of the specimen. Once the three thickness is obtained, the third value is averaged and the average thickness from the coating layer is obtained. The attachment testing is done by the Pull-Off method. This test is done in two parts and then the result of the adhesive power averaged and obtained the average adhesive strength of the coating layer. For the corrosion rate testing is done by immerse method. The solution used is a solution of $\mathrm{NaCl} 3.5 \%$ For 96 hours in accordance with ASTM 6-31. Before the test was carried out heavy weighing initial specimen first. The immerse or immersion process is performed for 96 hours. After the immersion process completed the specimen is done to get the final weight of the specimen. The corrosion rate calculation is done using the weightloss method (ASTM, 2004).

\section{Results and Discussion}

Specimens used were rectangular with a length of $5 \mathrm{~cm}$, width $4 \mathrm{~cm}$ and thickness of $0.4 \mathrm{~cm}$. Subsequently, the specimen was refined and cleaned before the electroplating process was carried out. The electrolyte solution used is the $\mathrm{ZnCl}_{2}$ solution with the addition of zylite additives and zylite brightener which is useful for leveling and brightening the results of the coating. Images of test specimens before and after the electroplating process are shown in Fig. 1.

Based on visual observations made, it can be seen that there are differences between the test specimens before the electroplating process and the test specimens after the electroplating process. The electroplating specimens appear brighter and more luminous than the specimens before the electroplating process looks more dull. From this 


\section{MATERIALS RESEARCH COMMUNICATIONS 1(1) (2020) 34-41}

\section{Vania}

observation it can also be seen that the specimen is well coated, ie the entire surface of the specimen has been coated with zinc metal $(\mathrm{Zn})$ which is used as a coating material evenly and thoroughly and there are no parts that are not coated with zinc metal (Zn).

As shown in Fig. 1, the specimens that have been electroplated have shown that the entire surface has a change in color and is more shiny than the specimens that have not been electroplated. This shows that the specimens that have been carried out electroplating process that is seen is the entire zinc metal electroplating deposits that cover the test specimen so that the original color or appearance of the test specimen is no longer visible.
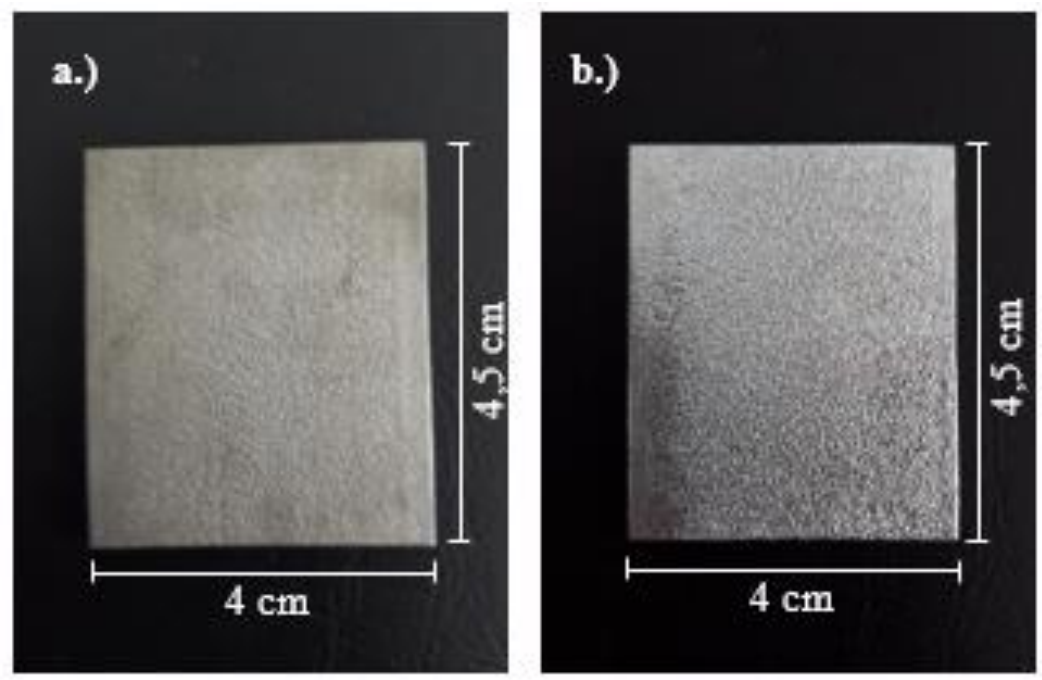

Fig. 1. (a) Surface of specimen before electroplating process and (b) after electroplating process.

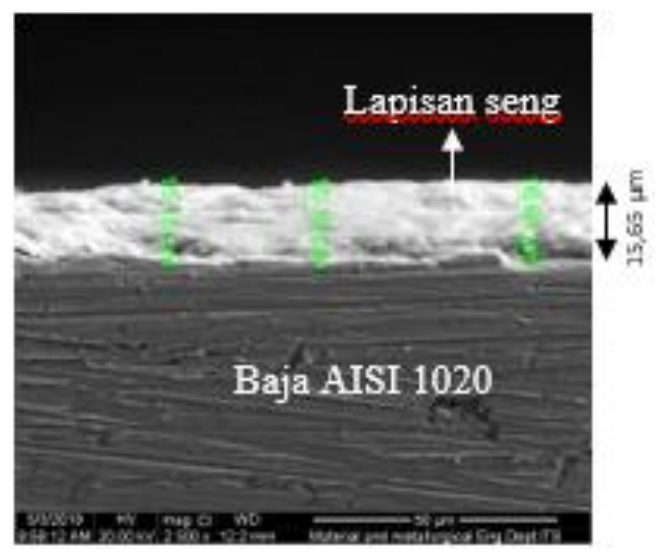

Fig. 2. (a) Scanning electron microscopy cross section area of electroplating specimen.

In Fig. 2. The zinc metal $(\mathrm{Zn})$ that looks brighter on the image is evenly deposited on the surface of the test specimen which looks darker on the image. This proves that the true $\mathrm{Zn}^{2+}$ metal ion deposition occurred on the surface of the test specimen. In this cross-section observation also measured the thickness of the layer. The thickness of the layers was measured at three points and the thickness values obtained from these three points were $15.15 \mu \mathrm{m}, 15.15 \mu \mathrm{m}$, and $16.67 \mu \mathrm{m}$. so the average thickness of the zinc layer is $15.65 \mu \mathrm{m}$. 
MATERIALS RESEARCH COMMUNICATIONS 1(1) (2020) 34-41

Vania

Table 1. EDX test result of Zn electroplating on AISI 1020 steel

\begin{tabular}{cccc}
\hline \hline Element & $\mathrm{Wt} \%$ & At \% \\
\hline $\mathrm{Zn}$ & 100 & 100 \\
\hline
\end{tabular}

As the data shown in Table 1. can be seen that the layer formed in the test specimen is composed of $100 \% \mathrm{Zn}$ elements. This shows that the elements deposited on the surface of the test specimen are fully $\mathrm{Zn}$ elements and there are no impurities. This also shows that the hole or pore formed on the surface of the coating is not a hole that penetrates to the test specimen but the hole or pore is only a hollow on the surface of the coating where the base of the basin is still part of the zinc layer $(\mathrm{Zn})$.

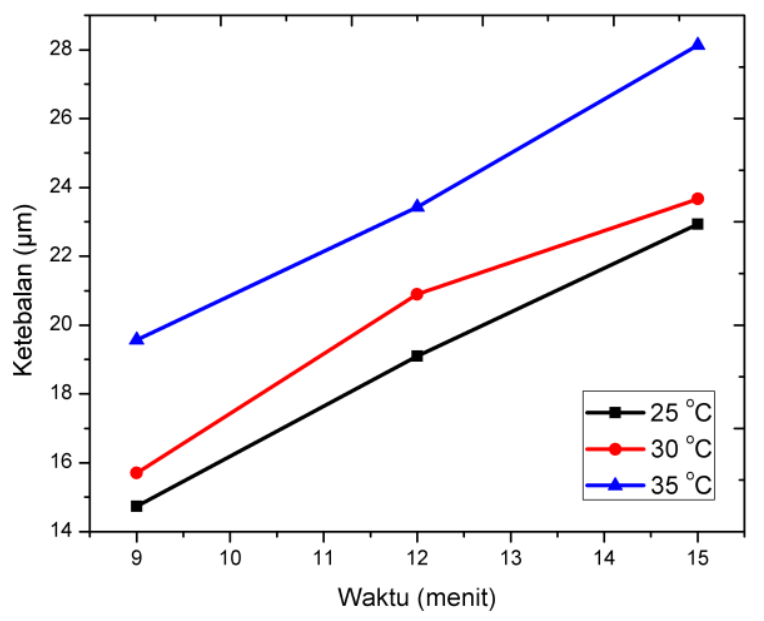

Fig. 3. Relation between temperature and time to $\mathrm{Zn}$ thickness coating

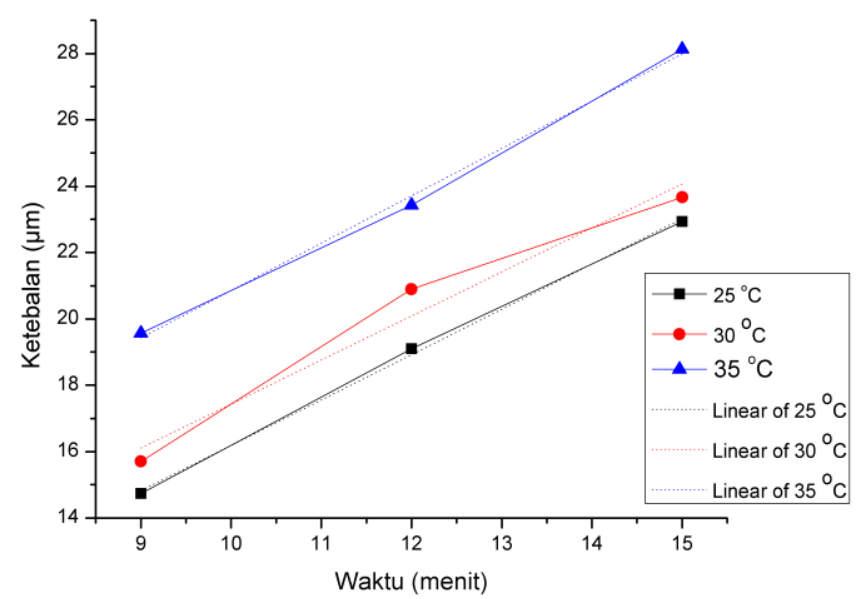

Fig. 4. Relation between temperature and time Zinc-electroplating to Zn thickness coating 


\section{MATERIALS RESEARCH COMMUNICATIONS 1(1) (2020) 34-41} Vania

Based on Fig. 3. shown the higher the temperature used in the electroplating process will produce a higher thickness value. According to Kumar (2015) by increasing the temperature of the electrolyte solution, the solubility in the solution will increase which will later increase the conductivity of the electrolyte solution. According to Yu (2013) the higher electrolyte conductivity will increase ion transport which can later increase deposition rate. In addition to the higher electrolyte temperature, the viscosity of the electrolyte solution will decrease which will cause the movement of the solution to be faster. Thus the deposition process will take place faster so as to produce a higher thickness value.

Based on the graph in Fig. 3. it can be seen that the longer the coating time used, the higher the thickness produced. According to Paunovic (2010) who discusses the concept of electrolysis based on Faraday's law explains that the electroplating process time affects the thickness of the resulting layer.

where:

$$
h=\frac{A w I t}{n F \rho A}
$$

$h=$ layer thickness

$A w=$ molecular weight

$I=$ current

$t=$ time

$n=$ number of electrons in the deposition reaction

$F=$ Faraday's constant

$\rho=$ density

$A=$ specimen surface area

In accordance with Equation 1. shown that coating time is directly proportional to the thickness of the resulting layer so that the longer the coating time is used, the resulting layer will be thicker. Based on ASTM B633-13 it is explained that the standard for zinc coating is $12 \mu \mathrm{m}$. So that from a total of 9 specimens the research variables all met the standard because all the thickness of the zinc layer produced was more than $12 \mu \mathrm{m}$. Based on the graph data in Fig. 3. a linear regression is then performed as shown in Fig. 4.

Based on the linear regression in Fig. 4, a mathematical equation is found in the relationship between temperature and electroplating time to the thickness of the zinc layer produced. For the electroplating process at $25^{\circ} \mathrm{C}$, the following equation is obtained

$$
\mathrm{y}=4.1 \mathrm{x}+10.722
$$

For the electroplating process at $30 \mathrm{oC}$, the following equation is obtained

$$
\mathrm{y}=3.9833 \mathrm{x}+12.122
$$

for the electroplating process at $35 \mathrm{oC}$, the following equation is obtained

$$
\mathrm{y}=4.2833 \mathrm{x}+15.144
$$

where $\mathrm{y}$ is the thickness of the zinc layer produced and $\mathrm{x}$ is the electroplating time. From these equations it can be estimated the time needed to obtain the desired thickness of the zinc layer with predetermined process parameters. 
MATERIALS RESEARCH COMMUNICATIONS 1(1) (2020) 34-41

Vania

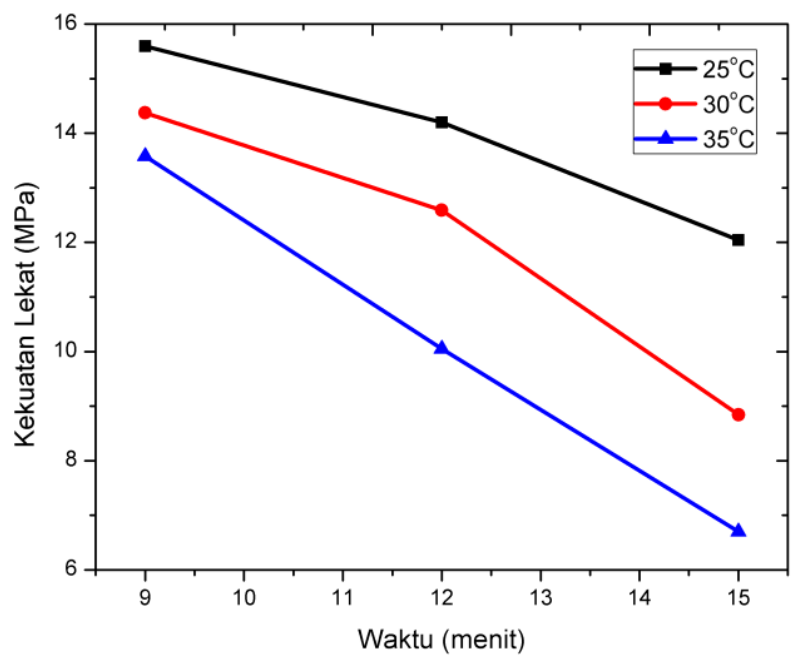

Fig. 5. Results of pull-off test at temperature and time variation.

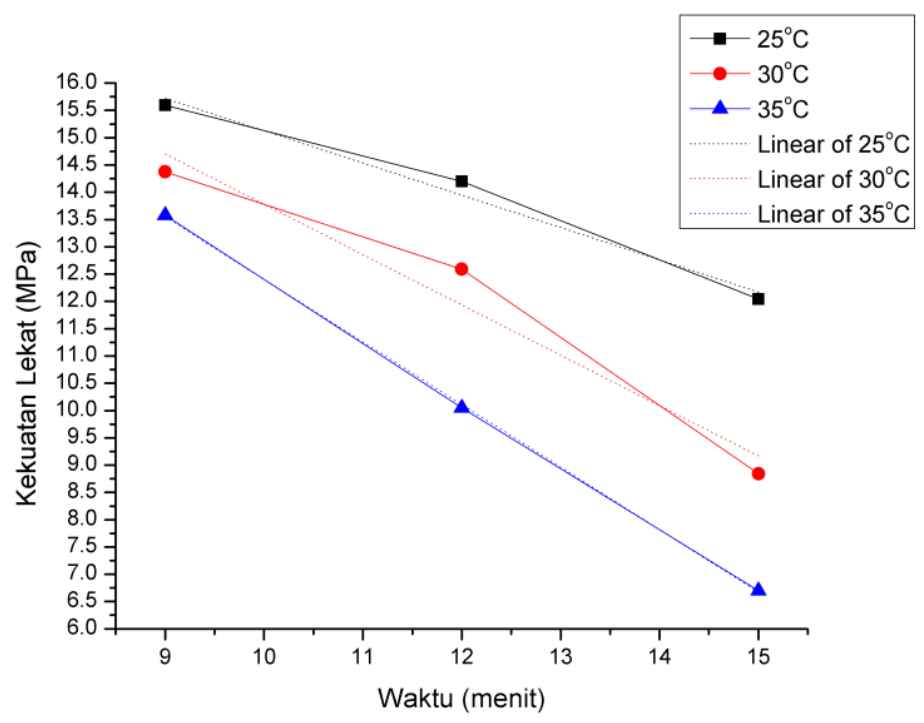

Fig. 6. Results of pull-off test at temperature and time variation.

Based on the graph in Fig. 5 it can be seen that the higher the temperature and the longer the time used for the electroplating process will reduce the value of the adhesive strength of the zinc layer produced. According to Antunes et al (2013) with the increase of the resulting coating layer it will cause a greater surface tension between the surface of the substrate with the coating results so that the sticky strength will decrease. In this research, it is known that increasing the temperature and time of the electroplating process will increase the thickness of the resulting layer so that it will reduce the adhesive strength between the coating layer and the substrate.

According to Malek (2013) the resulting coating must have a sticky strength of more than $7 \mathrm{MPa}$, less than that, the layer results will be rejected. In this study there is one test specimen with a thickness value below $7 \mathrm{MPa}$, namely C3 


\section{MATERIALS RESEARCH COMMUNICATIONS 1(1) (2020) 34-41} Vania

sample with a value of $6.700 \pm 0.593 \mathrm{MPa}$, which means that the results are rejected or unacceptable because it does not comply with the standard.

Based on the linear regression in Fig. 6., a mathematical equation is found in the relationship between temperature and electroplating time to the bonding strength of the zinc layer produced. For the electroplating process at $25^{\circ} \mathrm{C}$, the following equation is obtained

$$
y=-1.775 x+17.497
$$

for the electroplating process at a temperature of $30 \mathrm{oC}$ obtained the following equation

$$
y=-2.7675 x+17.47
$$

for the electroplating process at $35 \mathrm{oC}$, the following equation is obtained:

$$
y=-3.44 x+16.99
$$

where $\mathrm{y}$ is the bonding strength of the zinc layer produced and $\mathrm{x}$ is the electroplating time. From these equations it can be estimated the time needed to obtain the desired adhesive strength of the zinc layer with predetermined process parameters.

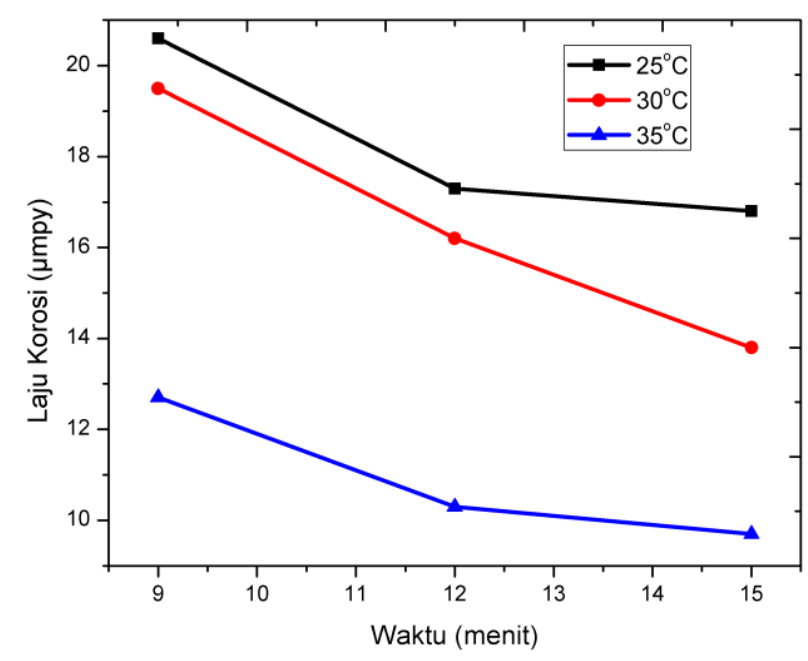

Fig. 7. Result of corrosion rate with weight loss method.

Based on Fig. 7. it can be seen that the higher the temperature and the longer time used during the electroplating process, the resulting corrosion rate decreases. This shows that the higher the temperature and the longer time used during the process of electroplating, the resulting corrosion resistance will increase. According to Idora (2014), the corrosion resistance of a steel coated with zinc depends on the thickness of the zinc layer produced. The thicker zinc coating that lines a steel sheet will increase the corrosion resistance. Sandoval (2017) also explained that the thickness of the zinc coating on a steel will increase the corrosion resistance of the steel because the thicker zinc layer on a steel will cause the penetration of corrosive ions towards the steel to become more difficult.

Based on ISO 19244 the corrosion rate of all samples falls into the low category because all corrosion rates of all samples are in the range 0.0013 to $0.025 \mathrm{mmpy}$. 


\section{MATERIALS RESEARCH COMMUNICATIONS 1(1) (2020) 34-41}

Vania

\section{Conclusions}

From this research can be concluded that the higher the temperature of electrolyte solution in the process of zinc electroplating then: the thickness of zinc coating is increasing with the highest thickness value of $28.13 \pm 1.34 \mu \mathrm{m}$ at $35^{\circ} \mathrm{C}$ temperature. Corrosion resistance increases with the least amount of corrosion rate of 0.0036 mmpy at $35^{\circ} \mathrm{C}$ temperature. As for the longer dyeing time in the process of zinc electroplating then the thickness of zinc coating is increasing with the highest thickness value of $28.13 \pm 1.34 \mu \mathrm{m}$ with dyeing time 15 minutes. The power of zinc coating is decreasing with the highest adhesive strength value of $15.695 \pm 0.261 \mathrm{MPa}$ with a 9-minute immersion time. Corrosion resistance increased with the least amount of corrosion rate of 0.0036 mmpy with time of 15 minutes.

\section{References}

Adetunji, O.R. 2010. "Optimizing Hot Dip Galvanizing Operations of Steel Sheets for Better Quality”. Journal of Natural Sciences, Engineering, \& Technology. Vol: 9 No: 2.

Alsultani, Kadhim F., et al. 2016. "Characterization of Electroplating by Using Zn-Nano Sized Al2O3 as Composite Coatings". Babylon University

Antunes, Jose Fernando, Brito, Vinisius Ribeiro dos Santos de Sa, Bastos, Ivan Napoleao, Costa, Hector Reynaldo Meneses. (2013). "Characterization of $\mathrm{FeCr}$ and $\mathrm{FeCoCr}$ alloy Coatings of Carbon Steels for Marine Environment Applications". Applied Adhesion Science 2013 1:3.

ASTM G31-72, 2004, Standard Practice for Laboratory Immersion Corrosion Testing of Metals. ASTM International, West Conshohocken, United States.

Callister, William. 2014. "Fundamentals of Materials Sciene and Engineering 9th Edition". New Jersey: John Wiley $\&$ Sons Inc.

Choe, Hong-Bok., et. al.. 2015. "Studying the Effect of Spraying Metal Type and Epoxy Sealing Coating Application on the Anti-Corrosion Properties of Arc Thermal Metal Spraying Film". Hanyang University.

Clifford, Biddulph. 2011. "Zinc Electroplating". Pavco Inc.

Cornaglia, L. M., et.al. 2017. "Comprehensive Materials Finishing”. Santa Fe: Universidad Nacional del LitoralCONICET

Giurlani, Walter., et, al. 2017 "Electroplating for Decorative Application: Recent Trends in Research and Development". Journal Coatings 22018. Vol: 8B. Smith, "An approach to graphs of linear forms (Unpublished work style)," belum dipublikasikan.

Idora, M.S. Noor., et.al. 2014. "Effect of Zinc Coating Thickness on Corrosion Performance of Mild Steel in Atmospheric and Seawater Environment". Applied Mechanics and Materials. Vol. 554: 213-217.

ISO 12944-2, 2017, Paints and varnishes -- Corrosion protection of steel structures by protective paint systems -- Part 2: Classification of environments. International Organization for Standardization, Genève, Switzerland

Milan, Paunovic dan Schlesinger Mordechay. 1998. "Fundamentals of Electrochemical Deposition". New York: John Wiley \& Sons, Inc.

Muhyidin, AM. 2016. "Pengaruh Penambahan Konsentrasi ZnSO4 terhadap Ketebalan, Sifat Adhesif, dan Ketahanan Korosi pada Baja ASTM 213 T11 dengan Metode Elektroplating". Surabaya: Institut Teknologi Sepuluh Nopember.

Ndariyono. 2011. "Pengaruh Temperatur Larutan Elektrolit, Rapat Arus Katoda Terhadap Ketebalan dan Adhesivitas Lapisan Pada Proses Elektroplating Tembaga-Nikel-Khrom”. Teknik Mesin FT-UNS. Surakarta.

Sandoval, A. Amador., et.al. 2017. "The Effect of Zinc Thickness on Corrosion Film Breakdown of Colombian Galvanized Steel". Journal of Physics : Series 935

Verhoeven, J.D. 2017. "Steel Metallurgy for the Non-Metallurgist. ASM International"J. Wang, "Fundamentals of erbium-doped fiber amplifiers arrays (Periodical style-Submitted for publication)," IEEE J. Quantum Electron., didaftarkan untuk dipublikasikan.

Wiewiorowska, Sylwia., dan Zbigniew Musklaski. 2015. "The Application of Low and Medium Carbon Steel with Multiphase TRIP Structure in Drawing Industry”. Jurnal Procedia Manufacturing Vol. 2. 